\title{
Azide-Novolak Resin Negative Photoresists for i-line Phase-Shifting Lithography
}

\author{
SHOUICHI UCHINO, TOSHIHIKO TANAKA, TAKUMI UENO, \\ TAKAO IWAYANAGI, and NOBUAKI HAYASHI \\ Central Research Laboratory, Hitachi Ltd. \\ Kokubunji, Tokyo 185, Japan
}

A photosensitive material called MRI consisting of an aromatic azide (4,4'diazido-3,3'-dimethoxybiphenyl) and a novolak resin has been prepared and evaluated as a negative resist for $\mathrm{i}$-line phase-shifting lithography. Due to the high transparency of this material $(80 \% / \mathrm{m})$ at the $\mathrm{i}-\mathrm{line}(365 \mathrm{~nm})$ and its high resist contrast $(\gamma=4) 0.3-\mu \mathrm{m}$ line-and-space patterns with a steep wall profile could be created by using i-line stepper with a phase-shifting mask. Groove patterns with a resolution of $0.13-\mu \mathrm{m}$ were obtained by using an edge-type phase-shifting mask.

\section{Introduction}

Much attention has recently been focused on i-line phase-shifting lithography as means of defining patterns during the fabrication of semiconductor devices. Patterns finer than the exposure wavelength can be made by using the phase-shifting lithography ${ }^{1,2}$ but no high-resolution negative resist has been available. An aromatic azide-cyclized poly-isoprene system has been reported but the resolution attainable with this resist is limited by the swelling-induced deformation of the resist patterns during development. We have reported non-swelling type negative resists based on an azidephenolic resin, but because of their strong absorbance at the exposure wavelength $(365 \mathrm{~nm})$, these resists can not make fine patterns with a vertical wall profile.

While studying negative deep-UV $3,4,5$ and mid-UV $(313 \mathrm{~nm})^{6}$ resists consisting of photosensitive aromatic azide compounds and various polymers, we found that a resist consisting of 4,4'-diazido-3,3'-dimethoxybiphenyl and a poly(4vinylphenol) is well suited to making high-resolution patterns. Surprisingly, this azide compound is also sensitive to i-line irradiation. This azide combined with a 
novolak resin to make an $\mathrm{i}$-line resist we call MRI (Micro Resist for $\mathrm{i}$-line) that meets the requirements of the i-line phase-shifting lithography.

\section{Experimental}

\section{I Materials and Resist Formulation}

The photosensitive azide, 4,4'-diazido-3,3'-dimethoxybiphenyl, was synthesized by diazotization of o-dianisidine followed by treatment with sodium azide. Novolak resins were obtained from Hitachi Chemical Co. and poly(4-vinyl-phenol) and its derivatives were obtained from Maruzen Oil Co. The azide was mixed with the phenolic resin to concentrations of 5 to $40 \%$ and dissolved in 2-ethoxyethyl acetate. After filtration, the resist solutions were spin-coated onto a silicon wafer. The resultant resist film was baked at $80^{\circ} \mathrm{C}$ for 10 minutes and subjected to lithographic evaluation.

\subsection{Resist Characterization}

Resist sensitivity and contrast were evaluated from sensitivity curves in which normalized film thickness was plotted as a function of the logarithm of exposure dose $\left(\mathrm{mJ} / \mathrm{cm}^{2}\right)$. The thickness of the resist remaining after development was measured with a Tencor Instruments Alpha-Step 200. The absorption spectra were measured with a Hitachi U-3410 spectrophotometer. The molecular weight and molecular weight distribution were determined by gel permeation chromatography (GPC) using a Hitachi 635 liquid-chromatography system.

\section{Results and Discussion}

\subsection{Spectroscopic Characterization}

A $0.6-\mu \mathrm{m}$-thick resist film of MRI was spin-coated onto a quartz plate and the UV spectra were measured before and after exposure. Figure 1 shows that the absorption at the i-line $(365 \mathrm{~nm})$ increases with exposure dose, and Fig. 2 shows the azide concentration dependence on the resist transmittance before and after exposure. The resist containing $30 \mathrm{wt} \%$ azide has an initial transmittance of about $80 \% / \mu \mathrm{m}$ and this resist's transmittance becomes $50 \% / \mu \mathrm{m}$ after $\mathrm{i}$-line exposure $\left(260 \mathrm{~mJ} / \mathrm{cm}^{2}\right)$. This darkening does not affect the fabrication of fine patterns (see Section 3.4).

\subsection{Resist Characteristics}

Figure 3 shows sensitivity curves for resists consisting of 4,4'-diazido-3,3'dimethoxy- biphenyl and various phenolic resins: poly(hydroxystyrene) (PHS, PHMC), brominated poly(hydroxystyrene) (PHS-Br), novolak resin, and m,p-cresol 


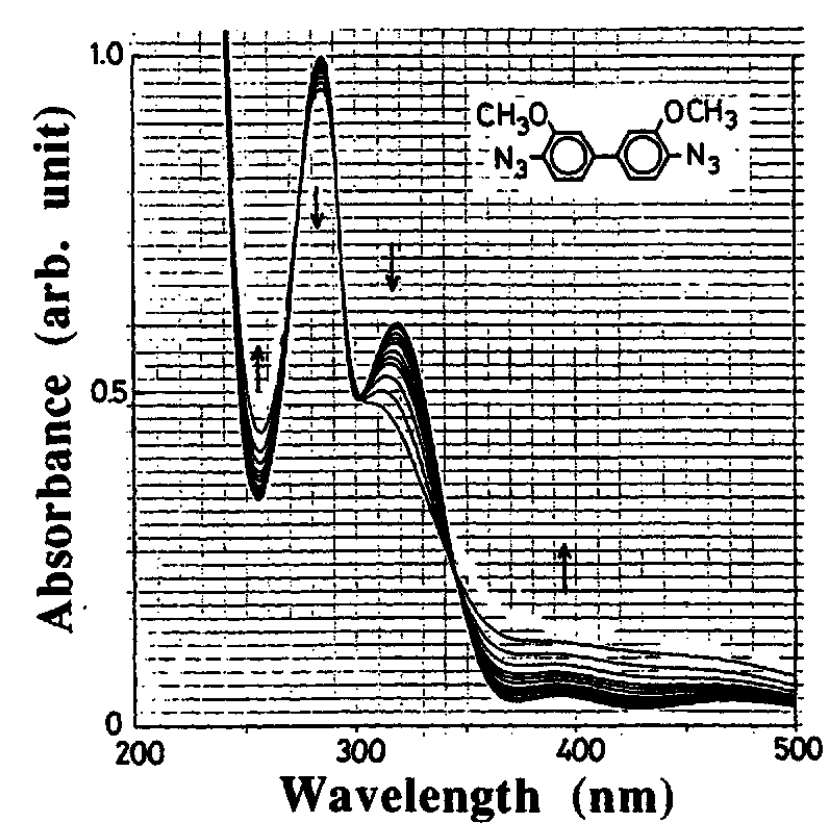

Fig. 1 UV absorption spectra of Novolak resin/4,4'-diazido3,3'-dimethoxybiphenyl=100/20 (wt. ratio).

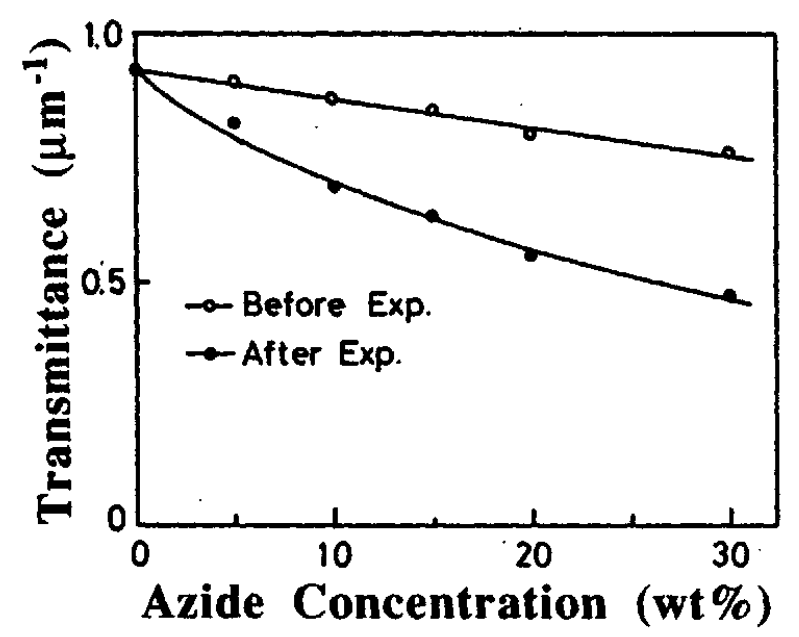

Fig. 2 Azide concentration dependence of resist transmittance before and after exposure $\left(260 \mathrm{~mJ} / \mathrm{cm}^{2}\right)$.

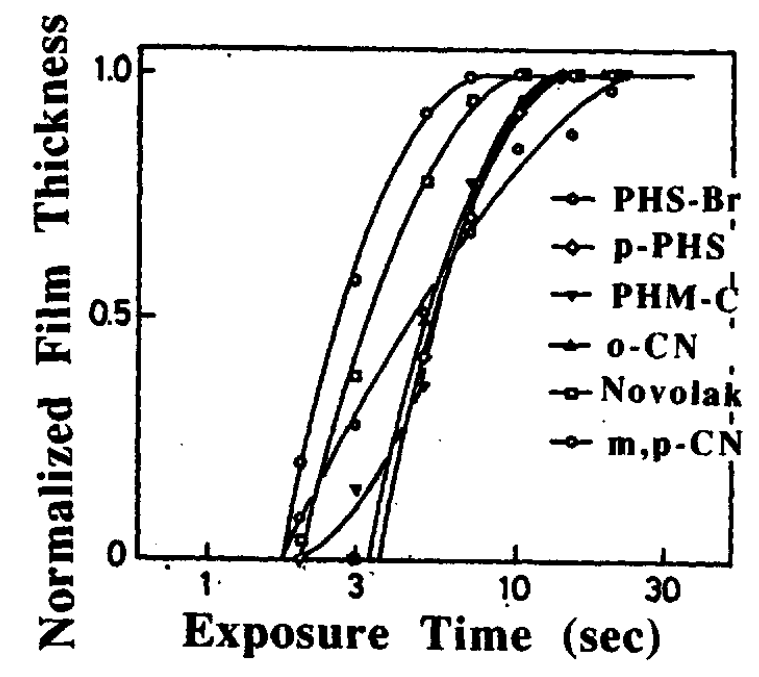

Fig. 3 Sensitivity curves of resists with various phenolic resins. [Novolak resin/ 4,4'-diazido-3,3'dimethoxybiphenyl=100/20 (wt, ratio)].

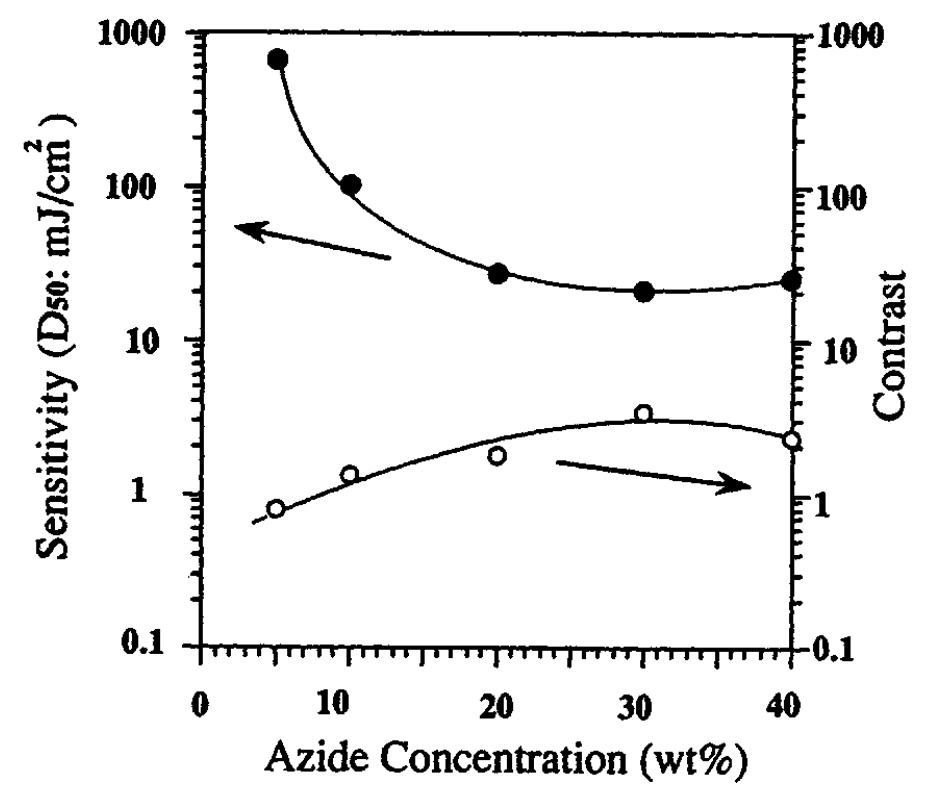

Fig. 4 Effect of azide concentration on MRI resist sensitivity. [Novolak resin/ 4,4'-diazido-3,3'dimethoxybiphenyl $=100 / \mathrm{X}$ (wt. ratio)]. 
novolak resin (m,p-CN). The $m, p$-cresol novolak resin showed the best lithographic performances of the phenolic resins evaluated. The resist sensitivity and contrast become higher with higher concentration of the azide and reaches a maximum at the $\mathbf{3 0}$ wt\% azide concentration (Fig. 4). Figure 5 shows the influence of the azide concentration on the resist film's dissolution characteristics, and it is also plots the ratio of unexposed films dissolution rate to that of the exposed films. This ratio increases markedly with increasing azide concentration. These dissolution should enable highresolution patterning to be created by using MRI.

\subsection{Resist Processing}

To determine appropriate development conditions, we examined the development time dependence on resist sensitivity and contrast. The resist contrast increases markedly with development time, while the sensitivity decreases little (Fig.6). Because it is necessary to develop resists for more than 5 times as long as the time needed to completely dissolve the unexposed region due to the low optical image contrast of exposure light around the resolution limit of exposure systems.

Figure 7 shows that the dissolution rate of the unexposed region decreases when the post-exposure baking temperature exceeded $80^{\circ} \mathrm{C}$, whereas the dissolution rate of the exposed region decreased at temperatures above $60^{\circ} \mathrm{C}$. This difference leads to an increased contrast between dissolution rates before and after exposure contrast of MRI if after exposure we bake the resist at $80^{\circ} \mathrm{C}$.

\subsection{Lithographic Characteristics}

Figure 8 is an SEM microphotograph of developed MRI resist patterns formed on a silicon wafer. Standing waves of the exposed light can be seen along the resist wall. Since the pitch of the standing wave is about $50 \mathrm{~nm}$, the resolution limit can be expected to be less than $50 \mathrm{~nm}$. Figure 9 shows the resist images of $0.3-\mu \mathrm{m}$ spaces and $0.35-\mu \mathrm{m}$ lines pairs formed on the anti-reflective layer (RG-3900B: Hitachi Chemical Co. ) by using a Levenson-type phase-shifting mask. Figure 10 shows $0.13-\mu \mathrm{m}$ groove patterns obtained by using the edge-type phase shifting-mask.

\subsection{Insolubilization Mechanism}

To elucidate the insolubilization mechanism of MRI, we made gel permeation chromatograms (GPC) of MRI before and after exposure. The GPC were obtained by monitoring the eluted materials at two wavelengths regions: $310-320 \mathrm{~nm}$ and $280-290$ $\mathrm{nm}$. It is possible to monitor the novolak resin and the azide photoproducts separately because the azide photoproducts absorb at $310-320 \mathrm{~nm}$ and the novolak resin has no absorption at these wavelengths. The molecular weight increase of novolak resin upon 


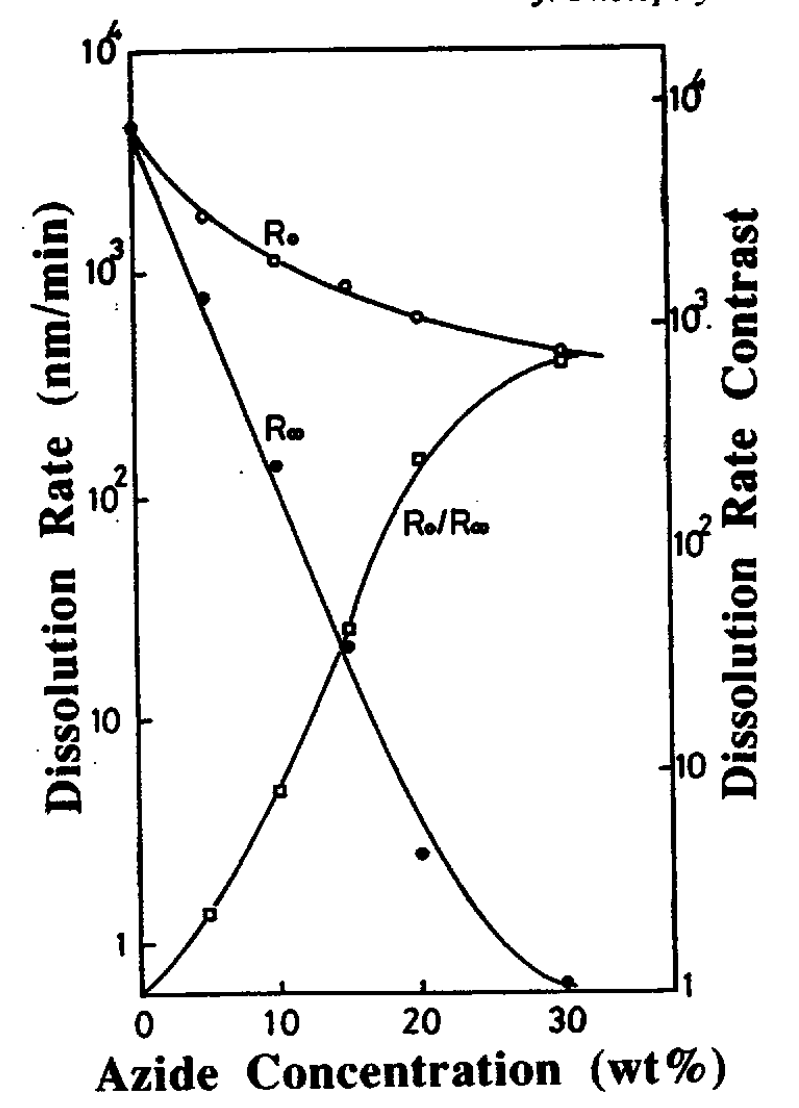

Fig. 5 Effect of azide concentration on resist film's dissolution before and after exposure $\left(260 \mathrm{~mJ} / \mathrm{cm}^{2}\right)$. [Novolak resin/4,4'-diazido-3,3'-dimethoxybiphenyl=100/X (wt. ratio)].

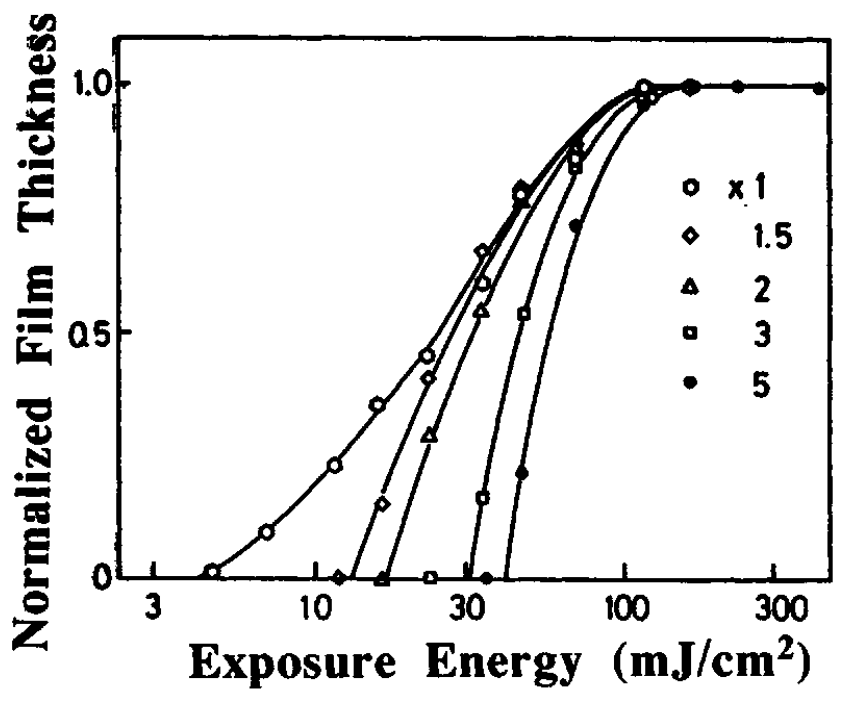

Fig. 6 Development time dependence of MRI resist sensitivity (curve labels shows development time in unit of the time needed to completely dissolve unexposed region).

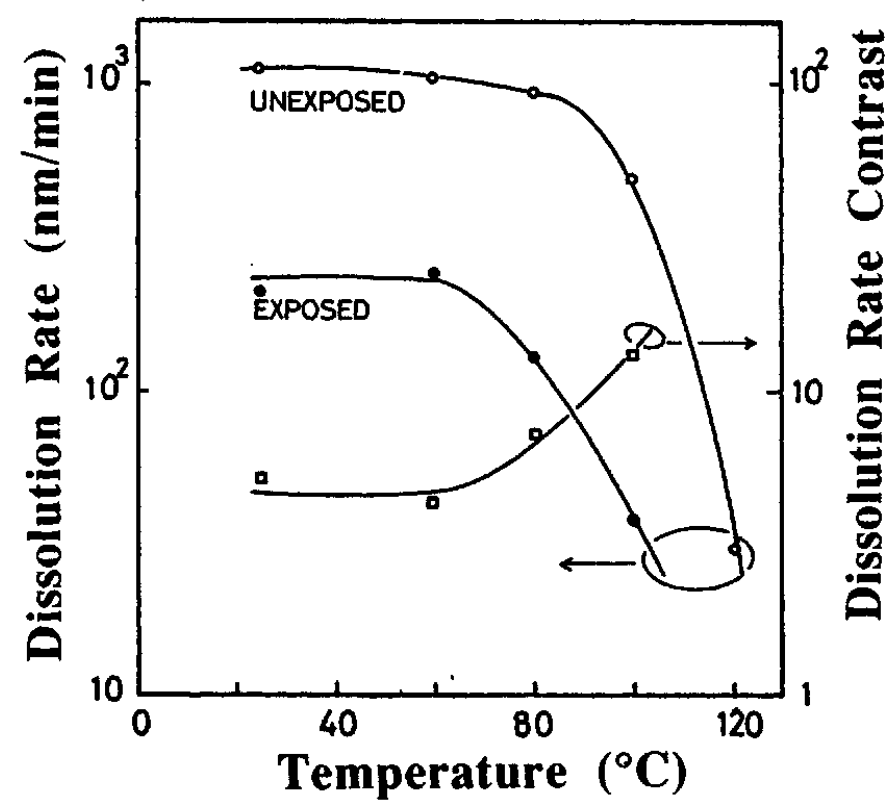

Fig. 7 Post-exposure baking temperature dependence on dissolution rates. [Novolak resin/4,4'-diazido-3,3'dimethoxybiphenyl=100/20 (wt. ratio). PEB time: $10 \mathrm{~min}$ ].
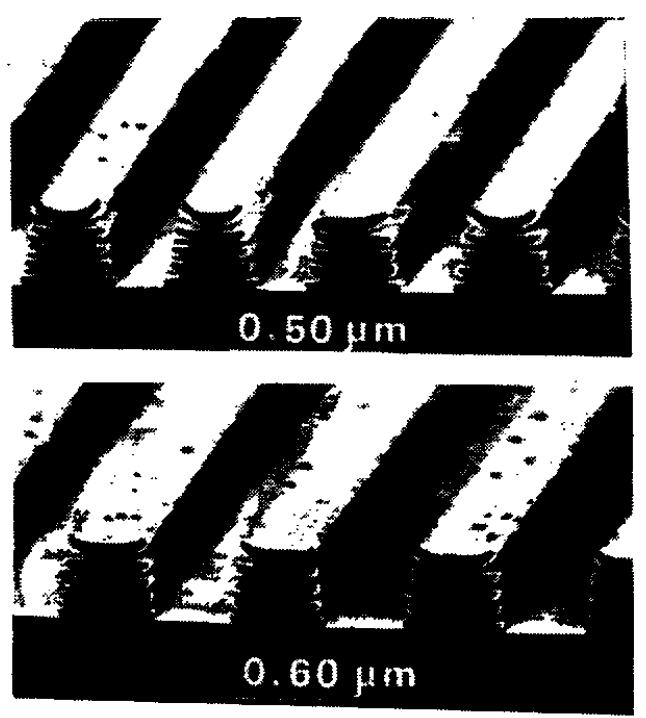

Fig. 8 Scanning electron micrograph of a developed MRI resist pattern formed on a silicon wafer. [Novolak resin/ 4,4'-diazido-3,3'-dimethoxybiphenyl=100/30 (wt. ratio). Film thickness: $0.5 \mu \mathrm{m}$, Dose $640 \mathrm{~mJ} / \mathrm{cm}^{2}$ ]. 


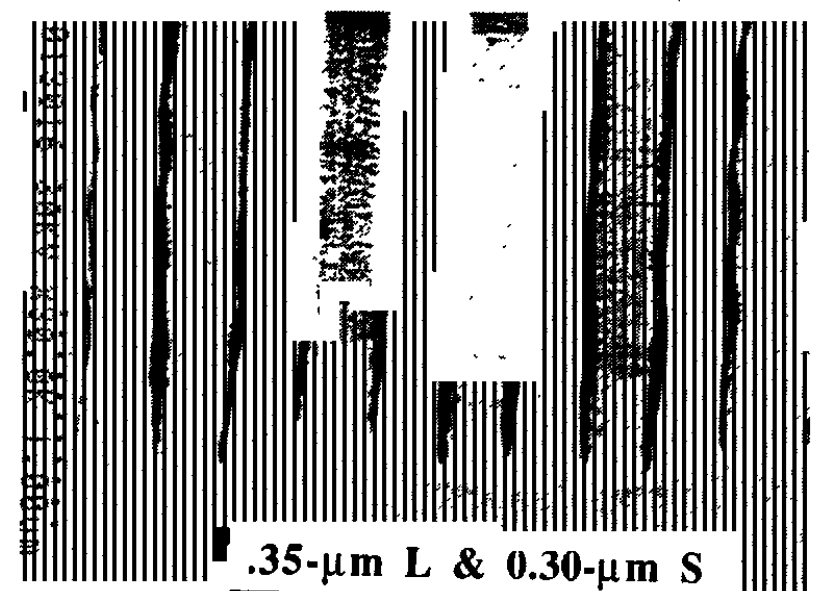

Fig. 9 Scanning electron micrograph of a developed MRI resist pattern produced by an i-line stepper in conjunction with a phase shifting mask. [Novolak resin/4,4'-diazido-3,3'dimethoxybiphenyl $=100 / 30$ (wt. ratio), Film thickness: $0.5 \mu \mathrm{m}$, Dose: $1 \mathrm{~J} / \mathrm{cm}^{2}$.

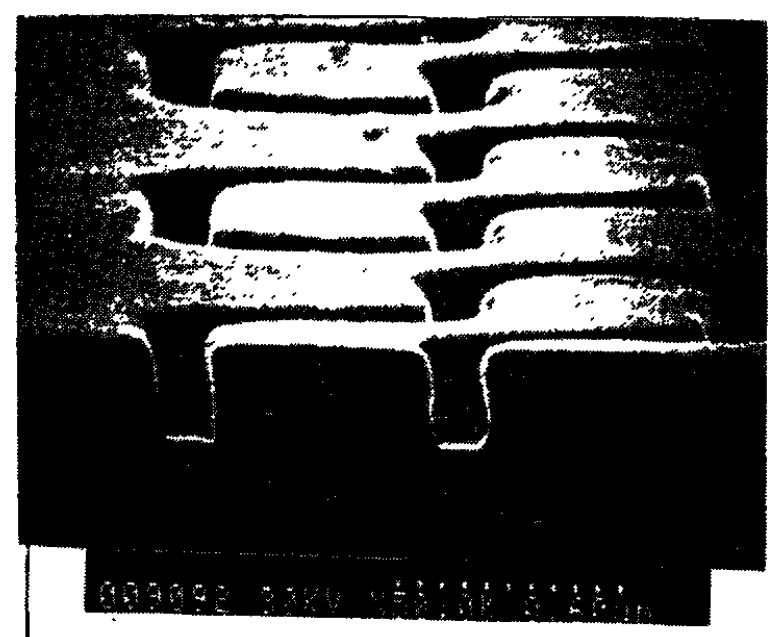

Fig. 10 Scanning electron micrograph of a developed MRI resist with $0.13-\mu \mathrm{m}$ groove patterns produce by using a phase-shifting mask. (Novolak resin/ 4,4'-diazido-3,3'dimethoxybiphenyl $=100 / 30$ (wt. ratio). Film thickness: $0.3 \mu \mathrm{m} \mid$.

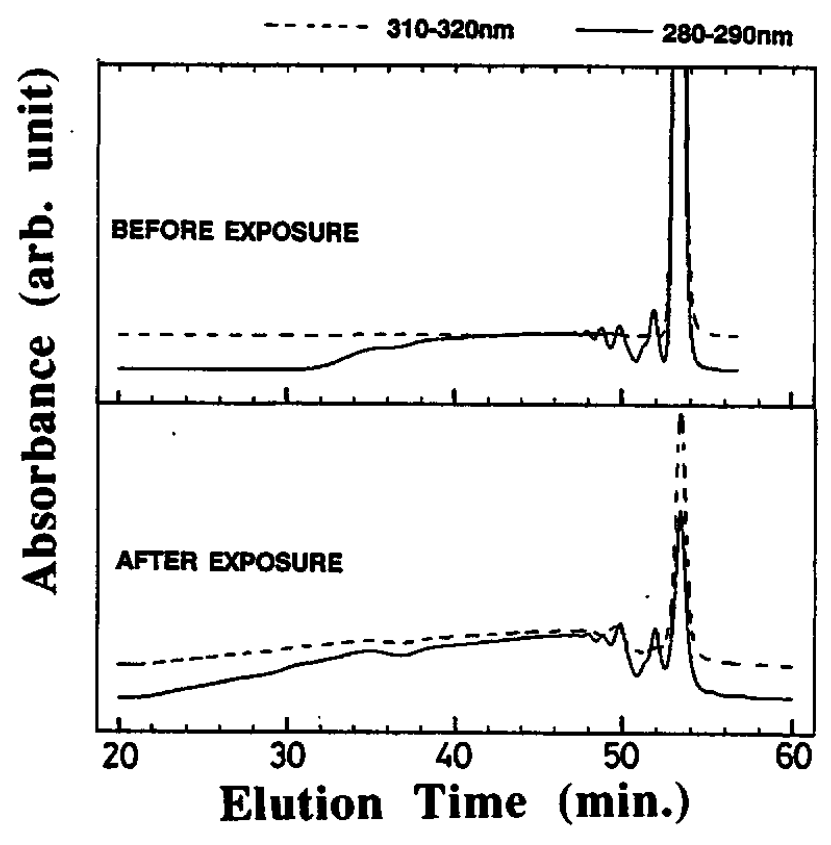

Fig. $11 \mathrm{Gel}$ permeation chromatogram of MRI before and after exposure. [Novolak resin/4,4'-diazido-3,3'dimethoxybiphenyl=100/20 (wt. ratio)]. 
i-line irradiation can be seen from the two solid lines in Figs. 11(a) and 11(b). In Fig. 11(b), the increase of the dashed line (photoproducts) with increasing elution time is similar to that of the solid line (novolak resin). This indicates that the azide photoproducts attach to the resin.

The solubility of the resin doped with primary amine (o-dianisidine) was the same as that of MRI. We therefore concluded that the insolubilization of exposed MRI in alkaline developers results from the formation of secondary amines.

\section{Conclusion}

A negative resist consisting of 4,4'-diazido-3,3'-dimethoxybiphenyl and a novolak resin meets the requirements needed for i-line phase shifting lithography. Images of $0.3-\mu \mathrm{m}$ space patterns and $0.35-\mu \mathrm{m}$ lines were created by using this resist in conjunction with a phase-shifting mask. The formation of secondary amines attached to the novolak resin makes this resist insoluble in alkaline solutions.

\section{Acknowledgements}

We thank Tsuneo Terasawa, Kouji Hattori, K. Kawabata and Nobuo Hasegawa for their help of $\mathrm{i}$-line exposure experiments. We also thank Toshio Sugiyama and Leo Schlegel for measuring spectral sensitivity, and we thank $T$. Yamanaka for his permission to use the phase-shifting masks he designed.

\section{References}

(1) M. D. Levenson, et al.; Improving Resolution in Photolithography with a PhaseShifting Mask, IEEE Trans. Electron Devices, vol. ED29, No. 12 , 1828 (1982).

(2) T. Terasawa et al.; 0.3-micron optical lithography using a phase-shifting mask, Proc. SPIE, 1088, 25 (1989).

(3) T. Iwayanagi et al.; Azide-Phenolic Resin UV Resist for Microlithography, Poly. Eng. and Sci., Vol. 23, 936 (1983).

(4) T. Iwayanagi, T. Kohashi, and S. Nonogaki, Azide Photoresists for deep-UV Lithography, J. Electrochem. Soc., Vol. 127, 2759, (1980).

(5) M. Toriumi et al.;A Negative Resist for KrF Excimer Laser Lithography, Poly. Eng. Sci.,28, 868, (1989).

(6) M. Toriumi et al; Negative Bleaching Photoresist (BLEST) for mid-UV Exposure, SPIE, 920, 27 (1988). 